\title{
The effect of temperature in flux-assisted synthesis of $\mathrm{SnNb}_{2} \mathrm{O}_{6}$
}

\author{
D. Noureldine, K. Takanabe \\ Division of Physical Sciences and Engineering, KAUST Catalysis Center (KCC), \\ King Abdullah University of Science and Technology (KAUST), 4700 KAUST, Thuwal, 23955- \\ 6900 Saudi Arabia
}

\begin{abstract}
A flux-assisted method was used to synthesize $\mathrm{SnNb}_{2} \mathrm{O}_{6}$ as a visible-light-responsive metal oxide photocatalyst. The role of synthesis temperature was investigated in detail using different reaction temperatures $(300,500$, $\left.600,800,1000{ }^{\circ} \mathrm{C}\right)$. The obtained products were characterized by X-ray diffraction (XRD), scanning electron microscopy (SEM), Brunauer-Emmett-Teller method (BET). The synthesis with $\mathrm{SnCl}_{2}$ as a flux led to tin niobate particles in the platelet morphology with smooth surfaces. The synthesized crystal showed 2D anisotropic growth along the (600) plane as the flux ratio increased. The particles synthesized with a high reactant to flux ratio (1:10 or higher) exhibited improved photocatalytic activity for hydrogen evolution from an aqueous methanol solution under visible radiation $(\lambda>420 \mathrm{~nm})$.
\end{abstract}

Keywords: $\mathrm{SnNb}_{2} \mathrm{O}_{6}$, flux-assisted synthesis, photocatalysis, hydrogen.

\section{INTRODUCTION}

Energy is currently one of the main focuses for worldwide research. Solar energy is the most promising renewable energy source to satisfy global energy demands. ${ }^{1-2}$ This is due to its favorable characteristics; such as being renewable, abundant, and green source of energy. Overall water splitting using photocatalysis has been introduced as a very promising candidate for future energy needs ${ }^{3-6}$ It has advantages of being simple, scalable, and clean technology. It produces a clean, renewable, and high-density energy carrier, i.e., hydrogen. This enables converting sunlight into a chemical form of energy that can be transportable. Many metal oxide photocatalysts have been studied for water splitting under UV irradiation due to their stability. ${ }^{7-9}$ However, they suffer from limited absorption in the UV region. Therefore, to be able to utilize sunlight, absorption should be shifted into the visible region and utilized for photocatalysis. ${ }^{10}$ One promising approach is to combine $\mathrm{d}^{0}$ transition metals $\left(\mathrm{Nb}^{5+}, \mathrm{W}^{5+}, \mathrm{Ta}^{5+}, \mathrm{V}^{5+}\right)$ with metals that have $\mathrm{s}^{2} \mathrm{~d}^{10}$ electron configurations, such as $\left(\mathrm{Sn}^{2+}, \mathrm{Bi}^{3+}, \mathrm{Pb}^{2+}\right) \cdot{ }^{11-14}$ The hybridization between $\mathrm{O} 2 \mathrm{p}$ and metal $\mathrm{s}^{2}$ orbitals results in a more strongly negative potential of the valence band than in oxides with only an $\mathrm{O} 2 \mathrm{p}$ contribution, thus minimizing the band gap.

$\mathrm{SnNb}_{2} \mathrm{O}_{6}$ is a promising visible-light-responsive photocatalyst with a band gap of $2.3 \mathrm{eV} .{ }^{15}$ It has been reported to evolve either hydrogen or oxygen using sacrificial agents, ${ }^{16}$ suggesting that it is capable to achieve overall water splitting. However, one of the main challenges of $\mathrm{Sn}^{2+}$ mixed metal oxide synthesis is that it suffers from the disproportionation of $\mathrm{Sn}^{2+}$ into $\mathrm{Sn}^{4+}$ and metallic $\mathrm{Sn}$ at high temperatures, which minimizes its activity especially when prepared by solid-state synthesis. ${ }^{17}$ In addition to that, the required high temperature for the synthesis does not offer control over the surface properties of photocatalytic materials, such as size, morphology and roughness. Hence, the synthesis method for $\mathrm{SnNb}_{2} \mathrm{O}_{6}$ materials must be carefully investigated.

In this context, hydrothermal methods ${ }^{19,20}$ and microwave-assisted synthesis ${ }^{21}$ have been used as low temperature synthesis methods which showed activity only for photocatalytic dye degradation applications. The obtained products showed a visible response, but their synthesis method led only to low crystallinity. ${ }^{19,21}$ Recently, $\mathrm{SnNb}_{2} \mathrm{O}_{6}$ synthesized by a hydrothermal method showed hydrogen evolution activity under visible light irradiation. ${ }^{20}$ The sample obtained by this method showed low crystallinity, but subsequent treatment at $800^{\circ} \mathrm{C}$ was found effective in increasing the crystallinity. This confirms that high temperatures are still needed to achieve hydrogen evolution. 
Flux-assisted synthesis is a commonly-used approach to obtain single crystal materials. This is achieved by dissolving the precursors in a molten salt that induces rapid diffusion and therefore the formation of products in shortened reaction times and at lower temperatures than the solid-state synthesis. ${ }^{18}$ The usage of lower temperatures and shorter reaction times compared to solid-state synthesis saves energy and reduces the cost, which is highly attractive in comparison with solid-state method. ${ }^{15,16}$ More interestingly, the flux-assisted method leads to the unique preferential growth of a specific facet that generally has lower interfacial energy than the other facets, which results in special morphologies, such as sheets, plates and flower-like shapes, that may have a beneficial effect on the photocatalytic activity of the material. ${ }^{22,23}$ Furthermore, this method leads to high crystallinity and non-defective materials via a recrystallization process that occurs while cooling down at certain temperatures. Kudo and coworkers reported the fluxassisted synthesis of $\mathrm{SnNb}_{2} \mathrm{O}_{6}$ starting from a $\mathrm{Sr}_{2} \mathrm{Nb}_{2} \mathrm{O}_{7}$ perovskite structure with $\mathrm{SnCl}_{2}$ as a molten salt. ${ }^{24}$ The synthesis proceeds through an ion exchange mechanism where $\mathrm{Sn}^{2+}$ replaces the $\mathrm{Sr}^{2+}$, resulting in a layered structure. However, they required a long reaction time $\left(30 \mathrm{~h}\right.$ ), and the process of removing the excess $\mathrm{SnCl}_{2}$ was quite difficult. They also reported the molten salt treatment of $\mathrm{NaNbO}_{3}$ nanorods and $\mathrm{Nb}_{2} \mathrm{O}_{5}$ nanowires with $\mathrm{SnCl}_{2}$, and the activity for hydrogen evolution using a sacrificial reagent was comparable to $\mathrm{SnNb}_{2} \mathrm{O} 6$ produced by solid-state synthesis. ${ }^{25}$ Still, there are many controllable factors, such as the choice of salt, the stoichiometric mixture, the heating temperature and the reaction time. $^{26}$

In previous work, we investigated the effects of flux ratio on the crystal growth of $\mathrm{SnNb}_{2} \mathrm{O}_{6}$ particles. The photocatalytic activity of the materials synthesized by the flux method was compared to the activity of the materials synthesized by the solid-state method. In this work we present a complementary study showing the effect of temperature, time, and nature of flux salt during the flux-assisted synthesis of $\mathrm{SnNb}_{2} \mathrm{O}_{6}$ for photocatalytic hydrogen evolution.

\section{EXPERIMENTAL}

\subsection{Synthesis of $\mathrm{SnNb}_{2} \mathrm{O}_{6}$}

Stoichiometric molar quantities of $\mathrm{SnO}$ (Sigma Aldrich, 99.99\%) and $\mathrm{Nb}_{2} \mathrm{O}_{5}$ (Aldrich, 99.99\%) were mixed homogenously by grinding for 20 min under an argon atmosphere. $\mathrm{SnCl}_{2}$ (Aldrich, $99.99 \%$ ) was added as a flux to with reactant to flux molar ratios 1:10 (1:10-F, F stands for flux). The mixture was ground again for $10 \mathrm{~min}$ under an argon atmosphere. The obtained mixture was transferred to an alumina boat and heated inside a tubular furnace under nitrogen flow with a flow rate of $100 \mathrm{ml} \mathrm{min}^{-1}$. Different reaction temperatures $(600,800,1000$ ${ }^{\circ} \mathrm{C}$ ) were tested for $10 \mathrm{~h}$, followed by radiative cooling to room temperature. The obtained samples were then washed by stirring overnight in Milli-Q water $\left(18.2 \mathrm{M} \Omega \mathrm{cm}^{-1}\right)$ to remove the remaining flux $\mathrm{SnCl}_{2}$. The obtained powders were dried at $70{ }^{\circ} \mathrm{C}$. Solid-state synthesis was performed by grinding for $30 \mathrm{~min}$ and heating for $10 \mathrm{~h}$ at $700,800,1000{ }^{\circ} \mathrm{C}$, as reported previously. ${ }^{15}$

\subsection{Characterization}

Powder X-ray diffraction (XRD) patterns were recorded with a BRUKER D8 Advance diffractometer (DMAX 2500) using a $\mathrm{Cu} \mathrm{K} \mathrm{K}_{\alpha}$ energy source at $40 \mathrm{kV}$ and $40 \mathrm{~mA}$. Scanning Electron Microscopy characterizations were performed on a Nova Nano 630 scanning electron microscope (SEM) from FEI Company. The electron beam energy was set to $5 \mathrm{keV}$ before the start of analysis. SEM measurements were used to determine the morphology as well as particle size of the synthesized particles. The SEM specimens were prepared by suspending them in ethanol and dispersing them by sonication. A drop of the solution was then poured onto the SEM stub and was dried before observations. The $\mathrm{N}_{2}$ sorption studies were conducted using a Micrometrics ASAP 2420 to determine the BrunauerEmmett-Teller (BET) surface area.

\subsection{Photocatalytic experiments}

Hydrogen evolution experiments were performed using a recirculating reactor unit. The accumulated gaseous products were analyzed using a Shimadzu GC 8A with a Molecular Sieve 13X column. Photocatalytic overall water 
splitting was performed under VIS light irradiation using a $300 \mathrm{~W}$ Xe lamp (CM1) with cutoff filter L42 ( $\lambda>420 \mathrm{~nm})$. Experiments were performed using $90 \mathrm{ml}$ of $\mathrm{H}_{2} \mathrm{O}, 10 \mathrm{ml}$ methanol and $100 \mathrm{mg}$ of photocatalyst was used. The platinum loading as cocatalyst was $1 \mathrm{wt} \%$ of the photocatalyst and it was loaded using wet impregnation method. The $\mathrm{Pt}^{4+}$ source was an aqueous solution of $\mathrm{H}_{2} \mathrm{PtCl}_{6}$. The mixture containing the photocatalyst and $\mathrm{Pt}^{4+}$ was heated while stirring until water completely evaporated. The obtained product was reduced under hydrogen flow at $250{ }^{\circ} \mathrm{C}$ for $1 \mathrm{~h}$.

\section{RESULTS AND DISCUSSION}

In our previous work, we investigated the role of flux ratio on the crystal structure and photocatalytic activity, and we concluded that the optimized reactant to flux molar ratio is $1: 10 .{ }^{27} \mathrm{In}$ order to study the effect of temperature on the synthesized products, we conducted synthesis of $\mathrm{SnNb}_{2} \mathrm{O}_{6}$ by both methods (solid state and flux-assisted synthesis) at different temperatures. Figure 1a shows the XRD pattern of samples prepared by solid state synthesis at different reaction temperatures $\left(700,800,1000{ }^{\circ} \mathrm{C}\right)$. It was observed that single phase $\mathrm{SnNb}_{2} \mathrm{O}_{6}$ were synthesized at temperatures of 800 and $1000^{\circ} \mathrm{C}$. At temperatures lower than $800{ }^{\circ} \mathrm{C}$ remaining starting materials were observed and remaining $\mathrm{SnO}$ was oxidized into $\mathrm{SnO}_{2}$. However for the flux-assisted synthesis it was observed in figure $1 \mathrm{~b}$ that pure phase of $\mathrm{SnNb}_{2} \mathrm{O}_{6}$ were synthesized at even $600{ }^{\circ} \mathrm{C}$. This confirms that the flux-assisted synthesis allowed obtaining the desired product at lower temperatures. Furthermore, it can be observed that samples prepared by flux method showed a preferential orientation along (600) plane at all temperatures. It is worth to mention that on the flux sublimation point is around 623 ${ }^{\circ} \mathrm{C}$ nevertheless still preferential orientation was observed at higher temperatures. This suggests that the molten salt plays a role in the nucleation and growth of $\mathrm{SnNb}_{2} \mathrm{O}_{6}$ where the energy of (600) is lowered due to complexation of chloride ions which triggers preferential growth along this plane.

a

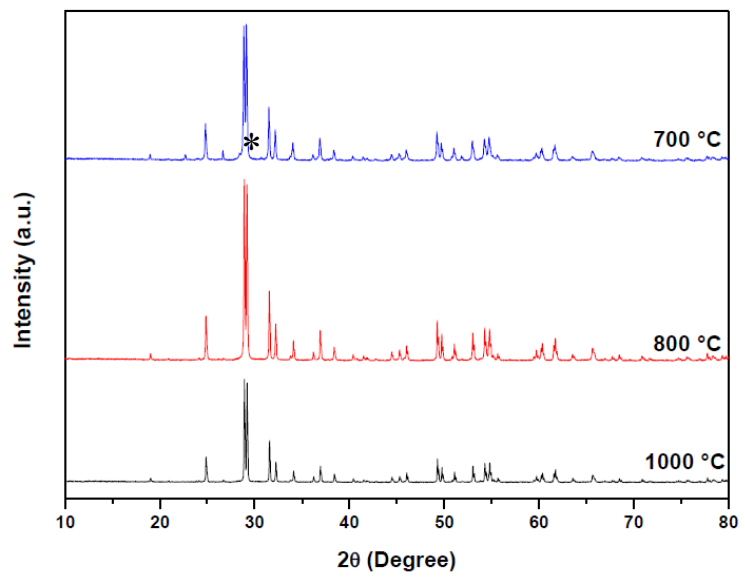

b

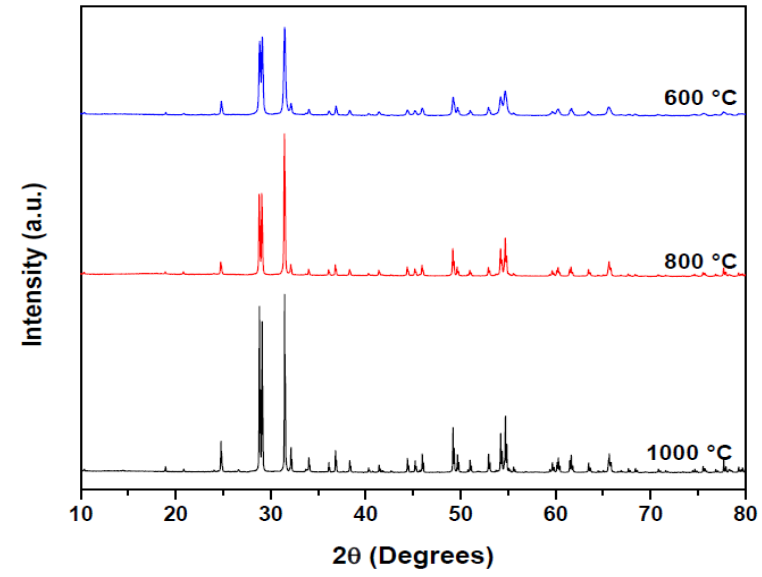

Figure 1: a) The XRD patterns of $\mathrm{SnNb}_{2} \mathrm{O}_{6}$ materials synthesized at 700,800 and $1000{ }^{\circ} \mathrm{C}$ by solid state method and b) by fluxassisted synthesis at 600,800 and $1000{ }^{\circ} \mathrm{C}$. The star indicates the main peak corresponding to $\mathrm{SnO}_{2}$.

We further investigated the effect of temperature in the flux-assisted synthesis at even lower temperatures. Figure 2 shows the XRD patterns of samples prepared at 500 and $300^{\circ} \mathrm{C}$. It can be observed that pure phase $\mathrm{SnNb}_{2} \mathrm{O}_{6}$ was obtained at $500^{\circ} \mathrm{C}$ with preferential growth as well. However at lower temperatures such as $300{ }^{\circ} \mathrm{C}, \mathrm{SnNb}_{2} \mathrm{O}_{6}$ was obtained but not in pure phase also no preferential growth was observed and crystallinity decreased. This can be explained by lowered solubility of starting precursors at lower temperatures which decreases the rate of growth of the crystal structure. 
The morphology of the obtained particles was monitored using SEM in figure 3. It was observed that materials prepared by solid state method showed a grain-like non uniform aggregated morphology. It can be observed that $\mathrm{SnNb}_{2} \mathrm{O}_{6}$ synthesized at $1000{ }^{\circ} \mathrm{C}$ showed greater particle size $(1 \mu \mathrm{m})$ than those prepared at $800{ }^{\circ} \mathrm{C}(300 \mathrm{~nm})$.

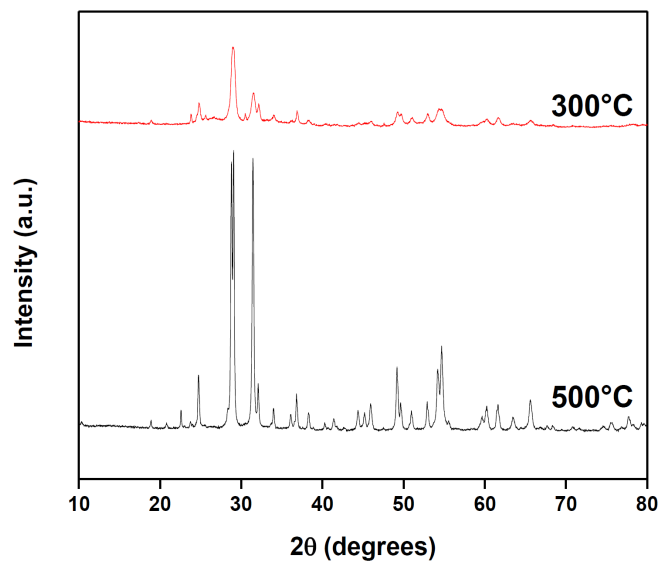

Figure 2: The $\mathrm{XRD}$ patterns of $\mathrm{SnNb}_{2} \mathrm{O}_{6}$ materials synthesized at 300 and $500{ }^{\circ} \mathrm{C}$ by the flux-assisted method.
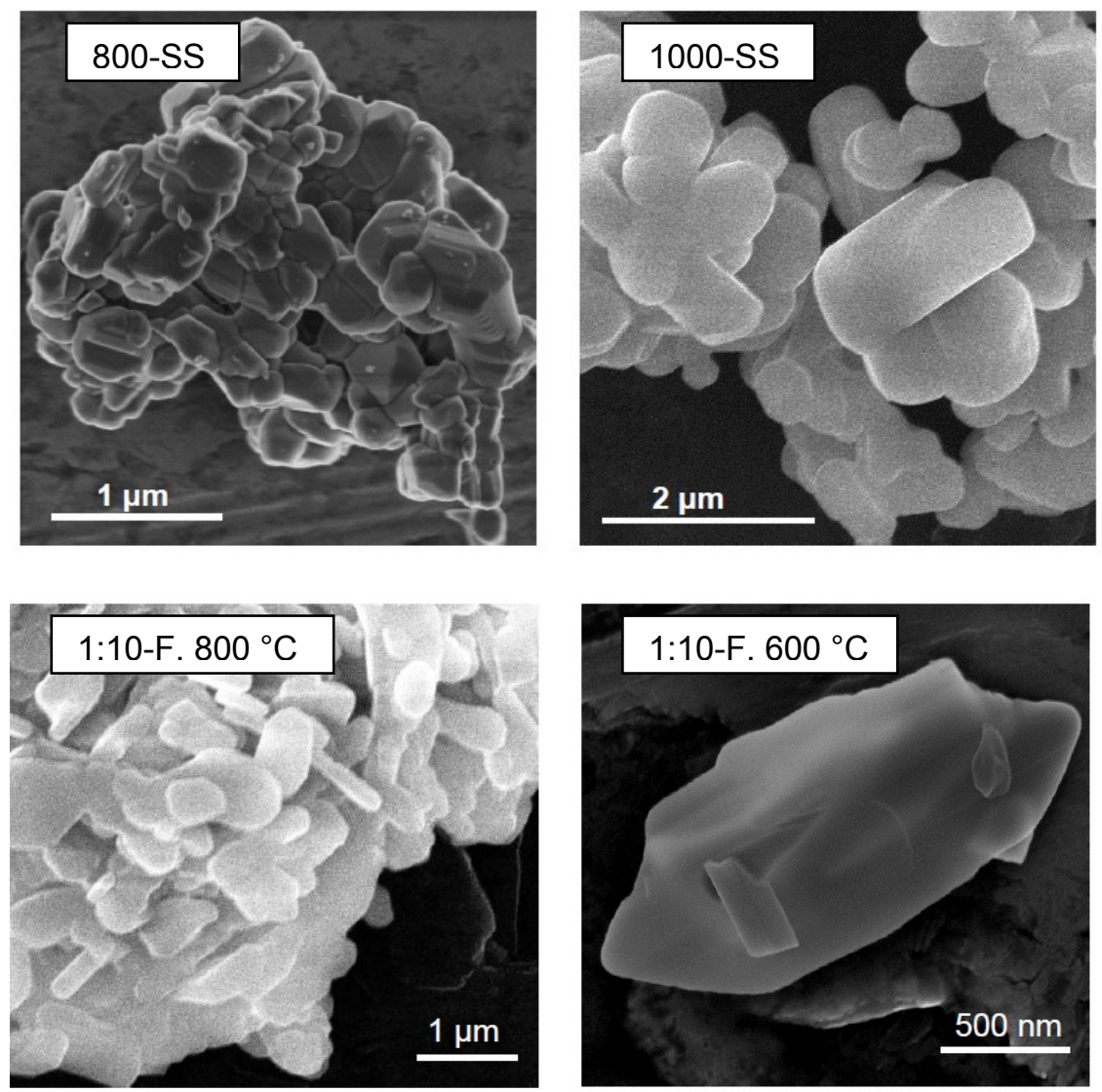

Figure 3: The SEM images of $\mathrm{SnNb}_{2} \mathrm{O}_{6}$ materials synthesized at 800 and $1000{ }^{\circ} \mathrm{C}$ by solid state method and by the flux-assisted synthesis at 800 and $600{ }^{\circ} \mathrm{C}$. 
By comparison to morphology of $\mathrm{SnNb}_{2} \mathrm{O}_{6}$ synthesized by flux-assisted synthesis, it can be clearly observed that $\mathrm{SnNb}_{2} \mathrm{O}_{6}$ prepared by flux synthesis at $600{ }^{\circ} \mathrm{C}$ (Fig. 3d) showed a plate like morphology which is a result of the 2D (in caxis) preferential growth. Similar morphology was observed at $500{ }^{\circ} \mathrm{C}$. However, at higher temperature of $800{ }^{\circ} \mathrm{C}$ (Fig. $3 \mathrm{c})$ the plates get more aggregated and the edges become less defined.

Table 1: BET surface area for samples prepared by solid state (800-SS and 1000-SS) and by flux-assisted synthesis $1: 10$-F $\left(500{ }^{\circ} \mathrm{C}\right)$, $1: 10-\mathrm{F}\left(600^{\circ} \mathrm{C}\right)$

\begin{tabular}{ll}
\hline Sample & BET surface area $\left(\mathrm{m}^{2} \cdot \mathrm{g}^{-1}\right)$ \\
\hline $800-\mathrm{SS}$ & 1.4 \\
$1000-\mathrm{SS}$ & 1.7 \\
$1: 10-\mathrm{F}-600^{\circ} \mathrm{C}$ & 5.2 \\
$1: 10-\mathrm{F}-500^{\circ} \mathrm{C}$ & 8.3 \\
\hline
\end{tabular}

The BET surface area of samples 1:10-F $\left(500^{\circ} \mathrm{C}\right), 1: 10-\mathrm{F}\left(600^{\circ} \mathrm{C}\right), 800-\mathrm{SS}$, and 1000-SS were summarized in Table 1. As the synthesis temperature increased, the surface area decreased. Therefore, another advantage of the fluxassisted synthesis is that it leads to large surface area materials due to low synthesis temperature. The photocataytic activity for hydrogen evolution reaction of $\mathrm{SnNb}_{2} \mathrm{O}_{6}$ samples 800 -SS and 1000 -SS synthesized at 800 and $1000{ }^{\circ} \mathrm{C}$, respectively, were compared to the sample prepared by the flux-assisted synthesis at $600{ }^{\circ} \mathrm{C}(10: 1-\mathrm{F})$. It was observed that 1:10-F showed higher hydrogen evolution rate $\left(35 \mu \mathrm{mol} \mathrm{h}^{-1}\right)$ than $800-\mathrm{SS}\left(20 \mu \mathrm{mol} \mathrm{h}^{-1}\right)$ which in turn showed higher activity than 1000-SS. This consequence of temperature can be explained by more oxidized $\mathrm{Sn}^{2+}$ into $\mathrm{Sn}^{4+}$ at higher temperatures which as act as recombination sites and therefore minimize the activity. It is worth mentioning that photocatalytic activity of the sample prepared using the flux-assisted synthesis at $800{ }^{\circ} \mathrm{C}$ decreased in comparison with $1: 10$-F reaching $7 \mu \mathrm{mol} \mathrm{h}^{-1}$. The oxygen evolution activity of 1:10-F showed $2.55 \mu \mathrm{mol} \mathrm{h}^{-1}$ and increased to $4.95 \mu \mathrm{mol} \mathrm{h}$ ${ }^{1}$ using $\mathrm{CoO}_{\mathrm{x}}$ as a catalyst.

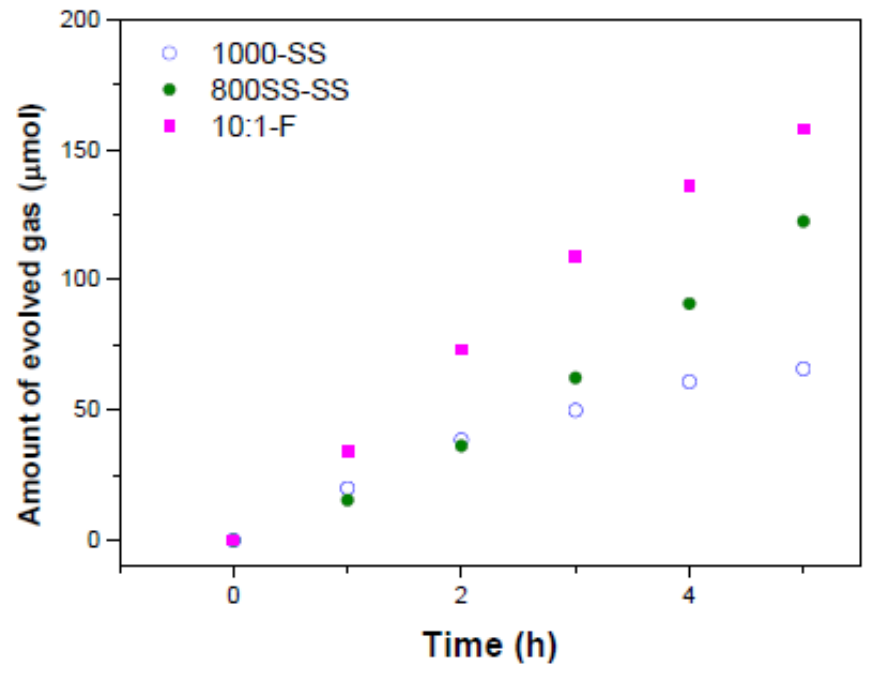

Figure 4: The hydrogen evolution activity of $\mathrm{SnNb}_{2} \mathrm{O}_{6}$ materials synthesized at $800{ }^{\circ} \mathrm{C}(800-\mathrm{SS})$ and $1000{ }^{\circ} \mathrm{C}(1000$ SS) by solid state method and by the flux-assisted synthesis at $600{ }^{\circ} \mathrm{C}(1: 10-\mathrm{F})$. 
Several salts were used as flux such as $\mathrm{Na}_{2} \mathrm{CO}_{3}$ and $\mathrm{K}_{2} \mathrm{WO}_{4}$ but the main product was alkali-incorporated oxide, such as $\mathrm{Na}_{2} \mathrm{Nb}_{2} \mathrm{O}_{6}$. This emphasizes the importance of $\mathrm{SnCl}_{2}$ as a self-flux to minimize impurities and to obtain the $\mathrm{SnNb}_{2} \mathrm{O}_{6}$ crystal structure.

\section{Conclusion}

The synthesis temperature of $\mathrm{SnNb}_{2} \mathrm{O}_{6}$ drastically affects the morphology of the material and resultant photocatalytic performance. The flux-assisted synthesis generates the $\mathrm{SnNb}_{2} \mathrm{O}_{6}$ samples with plate-like morphology because of a $2 \mathrm{D}$ anisotropic growth at $\geq 500{ }^{\circ} \mathrm{C}$. These plate-like morphology became less defined at lower temperatures than $300{ }^{\circ} \mathrm{C}$. The low temperature synthesis achieved by the flux-assisted synthesis compared to solid-state synthesis leads to high surface area. The photocatalytic activity of $\mathrm{SnNb}_{2} \mathrm{O}_{6}$ prepared by flux was higher than that prepared by

solid-state synthesis, clearly indicating the beneficial of lowering the synthesis temperature which may avoid the disproportionation of $\mathrm{Sn}^{2+}$ species.

\section{References}

[1] Lewis, N. S. and Nocera, D. G., Natl. Acad. Sci. U. S. A. 103, 15729-15735 (2007).

[2] Edenhofer, O., Seyboth, K., Creutzig, F. and Schlömer, S., Annu. Rev. Environ. Resour. 38, 169-200 (2013).

[3] Takanabe, K. and Domen, K., Green 1, 313-322 (2011).

[4] Domen, K., Kondo, J., Hara, M. and Takata, T., Bull. Chem. Soc. Jpn. 73, 1307 (2000).

[5] Domen, K., Korean J. Chem. Eng. 18, 862 (2001).

[6] Kato, H., Catal. Today 78, 561 (2003).

[7] Kato, H., Asakura, K. and Kudo, A., J. Am. Chem. Soc. 125, 3082 (2003).

[8] Kudo, A., Kato, H. and Tsuji, I., Chem. Lett. 33, 1534 (2004).

[9] Sato, J., Kobayashi, H., Ikarashi, K., Saito, N., Nishiyama, H. and Inoue, Y., J. Phys. Chem. B 108, 4369 (2004).

[10] Maeda, K., Teramura, K., Lu, D., Takata, T., Saito, N., Inoue, Y. and Domen, K., Nature 440, 295 (2006).

[11] Bodiot, D., Rev. Chim. Miner. 5, 569 (1968).

[12] Brisse, F., Stewart, D. J., Seidl, V. and Knop, O. , Can. J. Chem. 50, 3648 (1972).

[13] Cruz, L. P., Savariault, J. M., Rocha, J., Jumas, J. C. and Pedrosa de Jesus, J. D., J. Solid State Chem. 156, 349 (2001).

[14] Cerny, P., Fransolet, A.-M., Ercit, T. S and Chapman, R., Can. Mineral. 26, 889 (1988).

[15] Hosogi, Y., Tanabe, Y., Katol, H., Kobayashi, H. and Kudo, A., Chem. Lett. 33, 28 (2004).

[16] Hosogi, Y., Shimodaira, Y., Kato, H., Kobayashi, H. and Kudo, A., Chem. Lett. 20, 1299 (2008).

[17] Uma, S., Singh, J. and Thakral, V., Inorg. Chem. 48, 11624 (2009).

[18] Takanabe, K. and Domen, K., ChemCatChem. 4, 1485-1497 (2012).

[19] Liang, S., Zhu, S., Chen, Y., Wu, W., Wang, X. and Wu, L., J. Mater. Chem. 22, 2670 (2012).

[20] Seo, S. W., Noh, T. H., Park, S., Lee, C. W., Kim, S. H., Kim, H. J., Park, H. K. and Hong, K. S., Int. J. Hydrogen Energy, in press.

[21] Liang, S., Liang, R., Wen, L., Yuan, R., Wu, L. and Fu, X., Appl. Catal., B 125, 103-110 (2012).

[22] Akdogan, E. K., Brennan, R. E., Allahverdi, M. and Safari, A., J. Electroceram. 16, 159-165 (2006).

[23] Amutha, R., Muruganandham, M. G., Lee, J., Batalova, V. N., Mokrousov, G. and Wu, J. J., Adv. Sci. Lett. 3, 491-495 (2010).

[24] Hosogi, Y., Kato, H. and Kudo, A., Chem. Lett. 35, 578 (2006).

[25] Saito, K. and Kudo, A., Inorg. Chem. 52, 5621 (2013).

[26] Arney, D. H., Flux Synthesis of photocatalytic Transition Metal Oxides, PhD thesis, North California State University, Raleigh, NC, (2011).

[27] Noureldine, D., Anjum, D.H. and Takanabe, K., Phys.Chem.Chem.Phys. 16, 10762 (2014). 